\title{
BMJ
}

\section{Positive and negative affect and risk of coronary heart disease: Whitehall II prospective cohort study}

\author{
Hermann Nabi, research fellow, ${ }^{1,2}$ Mika Kivimaki, professor of social epidemiology, ${ }^{1}$ Roberto De Vogli, \\ lecturer, ${ }^{1}$ Michael G Marmot, head of department and director, ${ }^{1}$ Archana Singh-Manoux, senior research \\ fellow $w^{1,2,3}$
}

\begin{abstract}
${ }^{1}$ Department of Epidemiology and Public Health, University College London, London WC1E 6BT ${ }^{2}$ INSERM U687-IFR69, Villejuif, F-94807, France

${ }^{3}$ Hôpital Sainte Périne, Centre de Gérontologie, Paris, F-75781,

France

Correspondence to: $\mathrm{H}$ Nabi

H.Nabi@public-health.ucl.ac.uk

Cite this as: BMJ 2008;337:a118 doi:10.1136/bmi.a118
\end{abstract}

\section{ABSTRACT}

Objective To examine the associations between positive and negative affect and subsequent coronary heart disease events independently of established risk factors. Design Prospective cohort study with follow-up over 12 years.

Setting 20 civil service departments originally located in London.

Participants 10308 civil servants aged 35-55 years at entry into Whitehall II study in 1985.
Main outcome measures Fatal coronary heart disease, clinically verified incident non-fatal myocardial infarction, and definite angina ( $n=619$, mean follow-up 12.5 years). Results In Cox regression analysis adjusted for age, sex, ethnicity, and socioeconomic position, positive affect (hazard ratio $=1.01,95 \%$ confidence interval 0.82 to 1.24 ) and the balance between positive and negative affect, referred to as the affect balance score (hazard ratio $=0.89$, 0.73 to 1.09 ), were not associated with coronary heart disease. Further adjustment for behaviour related risk factors (smoking, alcohol consumption, daily fruit and vegetable intake, exercise, body mass index), biological risk factors (hypertension, blood cholesterol, diabetes), and psychological stress at work did not change these results. However, participants in the highest third of negative affect had an increased incidence of coronary events (hazard ratio=1.32, 1.09 to 1.60 ), and this association remained unchanged after adjustment for multiple confounders.

Conclusions Positive affect and affect balance did not seem to be predictive of future coronary heart disease in men and women who were free of diagnosed coronary heart disease at recruitment to the study. A weak positive association between negative affect and coronary heart disease was found and needs to be confirmed in further studies.

\section{INTRODUCTION}

Smoking, hypertension, hypercholesterolaemia, and diabetes are established risk factors for coronary heart disease, a leading cause of morbidity and mortality in Western industrialised countries. ${ }^{12}$ However, psychological factors, such as emotions, may also have a role in the development of coronary heart disease. ${ }^{34}$ Several prospective studies have found anxiety, hostility/ anger, and depression to be associated with an increased risk of coronary heart disease in healthy participants. ${ }^{35}$ As the relative importance of these three negative emotions on risk of coronary heart disease remains largely undefined, ${ }^{67}$ they have been hypothesised to be the components of a single underlying factor, labelled negative affect. Negative affect refers to "stable and pervasive individual differences in mood and self-concept characterised by a general disposition to experience a variety of aversive emotional states." 58 High negative affect has been described as a general tendency to report "distress, discomfort, dissatisfaction, and feelings of hopelessness over time and regardless of the situation," and low negative affect is characterised by "calmness and serenity." ${ }^{89}$ Supporting this conceptualisation, a considerable neurobiological and psychological overlap between anxiety, hostility/anger, and depression has previously been shown. ${ }^{1011}$

As attempts to link psychological factors to heart disease have focused on negative emotions, mostly depression, ${ }^{7}$ whether positive emotions might also have a role in the development of coronary heart disease remains unclear. Research suggests that positive affect and negative affect are two independent systems and that positive affect is not simply the opposite of negative affect or an absence of negative affect. $^{912}$ High positive affect refers to a general tendency to experience a "state of high energy, full concentration, and pleasurable engagement," whereas low positive affect is characterised by "sadness and lethargy." ${ }^{9}$ Distinct neural networks may exist to regulate positive and negative emotions; dopamine metabolism may be associated with positive affect and serotonin with negative affect, ${ }^{13}{ }^{14}$ supporting the assertion of the independence of the two types of affect.

We are aware of no previous large scale prospective studies on the independent effects of negative and positive affect on coronary heart disease. A six year follow-up of 2478 older participants in North Carolina found that positive affect was associated with decreased risk of stroke, but it did not examine coronary heart disease as an outcome, and the assessment of negative 
affect was limited to depressive symptoms. ${ }^{13}$ In this report from the Whitehall II study, we examine the independent associations of both negative affect and positive affect with subsequent coronary heart disease after taking account of established risk factors among participants followed up over 12 years. In addition, we examine whether the balance between positive and negative affect is associated with subsequent coronary heart disease.

\section{METHODS}

The Whitehall II study, established in 1985, is a longitudinal study to examine the socioeconomic gradient in health and disease among 10308 civil servants (6895 men and 3413 women). ${ }^{15}$ All civil servants aged 35-55 years in 20 London based departments were invited to participate by letter, and $73 \%$ agreed. Each participant gave written informed consent. Baseline examination (phase 1) took place during 1985-8 and involved a clinical examination and a self administered questionnaire.

\section{Measures}

We assessed positive affect and negative affect at phases 1 (1985-8) and 2 (1989-90) by using the Bradburn affect balance scale, ${ }^{16}$ a widely used measure of psychological wellbeing. The affect balance scale consists of 10 items, five of which are used to assess positive affect (Cronbach's $\alpha=0.80$ ) and the other five to assess negative affect (Cronbach's $\alpha=0.67$ ). All items are formulated in general terms, as questions about the participant's feelings during the previous few weeks. The items are phrased to elicit responses of the pleasurable or unpleasurable character of an experience instead of the context of the experience. Responses in this study are on a four point Likerttype scale from 0 (not at all) to 3 (a great deal). Scores for each subscale range from 0 to 15 ; higher scores indicate higher positive affect or higher negative affect. The affect balance score is calculated by subtracting the negative affect score from the positive affect score and adding a constant of 15 to avoid negative values. The affect balance score ranges from 0 (lowest affect balance) to 30 (highest affect balance). Neither natural thresholds nor clinically based thresholds are defined, so we divided each scale into low, middle, and high exposure on the basis of the distribution in the total study population-positive affect score thirds: lowest (0-4), middle (5-7), highest (8-15); negative affect score thirds: lowest (0-1), middle (2-3), highest (4-15); affect balance score thirds: lowest (0-16), middle (17-20), highest (21-30). Only 75\% of participants were asked to complete the affect balance scale at phase 1 , as this measure was introduced after the start of the baseline survey. Where phase 1 data were missing, we used positive and negative affect scores at phase 2 . The percentages of replacement were $15.0 \%$ for positive affect and $14.3 \%$ for negative affect. Correlation coefficients of scores at phase 1 (1985-8) and phase 2 (1989-90) suggest a moderate degree of consistency of positive affect $(r=0.52, \mathrm{P}<0.001)$, negative affect $(r=0.55 \mathrm{P}<0.001)$ and affect balance $(r=0.54, \mathrm{P}<0.001)$ across time.

We assessed the incidence of coronary heart disease from phase 2 (1989-90) to phase 7 (2003-4), a mean follow-up of 12.5 (SD 3.8) years. Coronary heart disease included fatal coronary heart disease (defined by the international classification of diseases, 9th revision (ICD-9) codes 410-414 or ICD-10 codes I2025), first non-fatal myocardial infarction, or first "definite" angina. We assessed fatal coronary heart disease by flagging participants at the NHS central registry, which provided information on the date and cause of death. We ascertained potential non-fatal myocardial infarction through questionnaire items on chest pain (the World Health Organization's Rose questionnaire ${ }^{17}$ ) and the physician's diagnosis of heart attack. We based confirmation of myocardial infarction according to MONICA (multinational monitoring of trends and determinants in cardiovascular disease ${ }^{18}$ ) criteria on electrocardiograms, markers of myocardial necrosis, and history of chest pain from the medical records. We assessed angina on the basis of participants' reports of symptoms with corroboration in medical records or abnormalities on a resting electrocardiogram, an exercise electrocardiogram, or a coronary angiogram.

\section{Covariates}

Sociodemographic measures included age, sex, and socioeconomic position assessed by British civil service grade of employment taken from the phase 1 questionnaire. Conventional risk factors assessed at phase 1 included smoking status (never, ex-smoker, and current), hypertension (systolic and diastolic blood pressure $>140 / 90 \mathrm{~mm} \mathrm{Hg}$ or treatment for hypertension), blood cholesterol $(<6.2$ or $\geq 6.2 \mathrm{mmol} / \mathrm{l})$, exercise $(\geq 1.5$ or $<1.5$ hours of moderate or vigorous exercise/ week), daily fruit and vegetable intake (yes/no), alcohol consumption in units of alcohol consumed a week (low: $<22$ for men and $<15$ for women; moderate: $22-51$ for men and 15-35 for women; or high: $>51$ for men and $>35$ for women), body mass index $(<20,20-24.9,25-$ 29.9 , or $\left.\geq 30 \mathrm{~kg} / \mathrm{m}^{2}\right)$, and self reported diabetes. Psychosocial stress at work (job strain) was measured at phase 1 with the self administrated job strain model questionnaire, ${ }^{19}$ including scales of psychological job demands, decision latitude, and social support at work..$^{2021}$ We replaced missing values at phase 1 with information at phase 2 .

\section{Statistical analyses}

We assessed differences in positive affect, negative affect, and affect balance scores as a function of sociodemographic characteristics and traditional coronary heart disease risk factors by using one way analysis of variance, with a linear trend fitted across the hierarchical variables. We used Cox regression to assess the age and sex adjusted association between various covariates and coronary heart disease.

We used six serially adjusted Cox regression models to model the associations of positive affect, negative 
Table 1 | Sample characteristics as a function of positive and negative affect subscales and affect balance scale scores ( $\mathrm{n}=8918)$

\begin{tabular}{|c|c|c|c|c|c|c|c|}
\hline \multirow[b]{2}{*}{ Variables } & \multirow[b]{2}{*}{ No } & \multicolumn{2}{|c|}{ Positive affect } & \multicolumn{2}{|c|}{ Negative affect } & \multicolumn{2}{|c|}{ Affect balance } \\
\hline & & Mean (SD) & $P$ value or for trend & Mean (SD) & $P$ value or for trend & Mean (SD) & $P$ value or for trend \\
\hline Sex: & & & $<0.001$ & & $<0.001$ & & $<0.001$ \\
\hline Male & 6093 & $6.20(2.91)$ & & $2.72(2.27)$ & & $18.48(4.01)$ & \\
\hline Female & 2825 & $5.81(3.19)$ & & $2.94(2.60)$ & & $17.87(4.59)$ & \\
\hline Age (years): & & & 0.002 & & $<0.001$ & & $<0.001$ \\
\hline $39-45$ & 2469 & $6.15(2.96)$ & & $3.15(2.42)$ & & $18.06(4.23)$ & \\
\hline $45-50$ & 2340 & $6.19(2.98)$ & & $2.92(2.41)$ & & $18.26(4.24)$ & \\
\hline $50-55$ & 1827 & $6.03(3.07)$ & & $2.63(2.32)$ & & $18.40(4.19)$ & \\
\hline $55-64$ & 2282 & $5.91(3.02)$ & & $2.40(2.29)$ & & $18.51(4.16)$ & \\
\hline Employment grade: & & & $<0.001$ & & 0.005 & & $<0.001$ \\
\hline High & 2704 & $6.55(2.80)$ & & $2.67(2.19)$ & & $18.88(3.87)$ & \\
\hline Middle & 4370 & $6.06(2.99)$ & & $2.84(2.36)$ & & $18.21(4.18)$ & \\
\hline Low & 1844 & $5.44(3.20)$ & & $2.85(2.69)$ & & $17.58(4.61)$ & \\
\hline Ethnicity: & & & $<0.001$ & & 0.553 & & $<0.001$ \\
\hline White & 8134 & $6.17(2.95)$ & & $2.79(2.36)$ & & $18.39(4.16)$ & \\
\hline Other & 784 & $5.01(3.39)$ & & $2.84(2.64)$ & & $17.17(4.58)$ & \\
\hline Hypertension: & & & 0.147 & & $<0.001$ & & 0.113 \\
\hline No & 7273 & $6.10(3.00)$ & & $2.85(2.39)$ & & $18.25(4.22)$ & \\
\hline Yes & 1645 & $5.98(3.04)$ & & $2.55(2.34)$ & & $18.44(4.15)$ & \\
\hline Smoking status: & & & 0.992 & & $<0.001$ & & 0.018 \\
\hline Never smoker & 4461 & $6.02(2.99)$ & & $2.71(2.31)$ & & $18.31(4.12)$ & \\
\hline Ex-smoker & 2893 & $6.25(3.02)$ & & $2.80(2.33)$ & & $18.45(4.20)$ & \\
\hline Current smoker & 1564 & $5.92(3.01)$ & & $3.01(2.67)$ & & $17.90(4.43)$ & \\
\hline Alcohol consumption: & & & 0.028 & & $<0.001$ & & 0.527 \\
\hline Low & 7515 & $6.04(3.00)$ & & $2.76(2.37)$ & & $18.29(4.20)$ & \\
\hline Moderate & 1198 & $6.30(3.00)$ & & $2.92(2.38)$ & & $18.38(4.21)$ & \\
\hline High & 205 & $6.10(3.09)$ & & $3.36(2.64)$ & & $17.75(4.51)$ & \\
\hline Exercise (hours/week): & & & $<0.001$ & & $<0.001$ & & $<0.001$ \\
\hline$\geq 1.5$ & 1659 & $6.83(2.98)$ & & $2.59(2.20)$ & & $19.24(4.00)$ & \\
\hline$<1.5$ & 7259 & $5.90(2.98)$ & & $2.84(2.42)$ & & $18.07(4.22)$ & \\
\hline Daily fruit and vegetables: & & & $<0.001$ & & $<0.001$ & & $<0.001$ \\
\hline Yes & 5260 & $6.26(3.03)$ & & $2.72(2.36)$ & & $18.54(4.22)$ & \\
\hline No & 3658 & $5.82(2.95)$ & & $2.90(2.41)$ & & $17.92(4.16)$ & \\
\hline Body mass index: & & & 0.234 & & 0.001 & & 0.005 \\
\hline$<20$ & 539 & $5.63(3.06)$ & & $3.19(2.49)$ & & $17.43(4.42)$ & \\
\hline $20-24.9$ & 4960 & $6.11(2.96)$ & & $2.81(2.37)$ & & $18.30(4.13)$ & \\
\hline $25-29.9$ & 2850 & $6.14(3.02)$ & & $2.68(2.34)$ & & $18.45(4.23)$ & \\
\hline$\geq 30$ & 569 & $5.92(3.23)$ & & $2.78(2.54)$ & & $18.14(4.56)$ & \\
\hline Diabetes: & & & 0.048 & & 0.055 & & 0.13 \\
\hline No & 8837 & $6.08(3.00)$ & & $2.79(2.39)$ & & $18.30(4.20)$ & \\
\hline Yes & 81 & $5.42(3.26)$ & & $3.30(2.33)$ & & $17.12(4.59)$ & \\
\hline Job strain: & & & $<0.001$ & & $<0.001$ & & $<0.001$ \\
\hline No & 7859 & $6.22(2.99)$ & & $2.67(2.31)$ & & $18.55(4.12)$ & \\
\hline Yes & 1059 & $5.03(2.87)$ & & $3.66(2.68)$ & & $16.37(4.33)$ & \\
\hline Blood cholesterol $(\mathrm{mmol} / \mathrm{l})$ : & & & 0.179 & & $<0.001$ & & 0.107 \\
\hline$\ll 6.2$ & 5424 & $6.11(3.01)$ & & $2.88(2.41)$ & & $18.23(4.26)$ & \\
\hline$\geq 6.2$ & 3494 & $6.02(2.99)$ & & $2.65(2.33)$ & & $18.38(4.13)$ & \\
\hline
\end{tabular}

affect, and affect balance scores with incident coronary heart disease. We adjusted model 1 for the association between positive affect and incident coronary heart disease for sex, age, ethnicity, and employment grade (that is, potential confounding factors), and the subsequent models included potential mediators for the association. Thus, in addition to potential confounders, we adjusted model 2 for behaviour related risk factors, model 3 for biological risk factors, and model 4 for psychosocial stress at work. We adjusted model 5 for all of the covariates outlined above and model 6 for negative affect. We repeated this whole exercise starting out with negative affect (using positive affect in model 6) and the affect balance score. We also checked for interactions between affect measures and sex in relation to coronary heart disease on a 
multiplicative scale. The assumption of proportional hazards assessed by examining the time dependent interaction term between each predictor and logarithm of the follow-up period (time variable) held (all $\mathrm{P}>0.05)$.

\section{RESULTS}

Of the 9745 participants with no history of clinically validated coronary heart disease at phase 2, 9568 (98.1\%) completed the positive affect subscales and $9605(98.6 \%)$ completed the negative affect subscales, either at phase 1 or phase 2. Among the 8918 participants with complete data on positive and negative affect and all covariates, 619 coronary events were documented between phases 2 and 7 . The 827 participants who were not included in the analyses owing to missing data on affect scales $(\mathrm{n}=614)$ or on covariates $(\mathrm{n}=213)$ were more likely than the included participants to be women (11.5\% v 7.0\%), non-white $(15.7 \%$ v $7.0 \%)$, and from the lowest employment grade $(13.1 \% v 7.2 \%)$. No difference in age was seen.

Table 1 shows the difference in mean positive affect, negative affect, and affect balance scores as a function of the characteristics of the sample. Table 2 shows the age and sex adjusted associations between all of the covariates and coronary heart disease events. Examination of the interactions between sex and the affect variables in relation to coronary heart disease showed no evidence of sex differences. Therefore, we combined men and women in the subsequent multivariate analyses.

Associations of positive affect, negative affect, and affect balance score with coronary heart disease

Table 3 shows the six serially adjusted Cox regression models designed to estimate the associations of affect measures with coronary heart disease. We found no association between higher positive affect scores and the incidence of coronary heart disease (hazard ratio $1.01,95 \%$ confidence interval 0.82 to 1.24 ) in the analysis adjusted for age, sex, socioeconomic position, and ethnicity (model 1) or after further adjustment for behaviour related risk factors (model 2), biological risk factors (model 3), psychological stress at work (model 4), all covariates (model 5), and negative affect (model 6). However, participants with negative affect scores in the highest third had a slightly higher risk (hazard ratio $1.32,1.09$ to 1.60$)$ of coronary heart disease (model 1). Further serial adjustment (models 2 to 6) showed no substantial change in this association. Finally, participants with affect balance scores in the highest third had a lower, but statistically non-significant, risk (hazard ratio $0.89,0.73$ to 1.09 ) of coronary heart disease, which was little affected by adjustments (models 2 to 6 ).

\section{Sensitivity analysis}

To explore the effect of unmeasured comorbidity at baseline, we examined the association between negative affect and incidence of coronary heart disease events after removing from the analysis any events that occurred within the first five years of the follow-up. The number of events was reduced by $31.5 \%(\mathrm{n}=424)$ in this analysis, but we found no change in the magnitude of the association between higher negative affect and coronary heart disease (hazard ratio adjusted for age, sex, ethnicity, and socioeconomic position $1.32,1.05$ to 1.67; $\mathrm{P}=0.016$ ), suggesting that this association is unlikely to be attributable to unmeasured comorbidity at baseline. In the main analysis reported in this paper, we have replaced missing negative affect scores at phase 1 with scores at phase 2 if available. We did sensitivity analysis using negative affect scores at each phase to test their association with coronary heart disease incidence without any replacement. In both

Table 2|Age and sex adjusted associations between covariates and coronary heart disease among 8918 participants (619 events)

\begin{tabular}{|c|c|c|}
\hline \multirow[b]{2}{*}{ Variables } & \multicolumn{2}{|c|}{ Risk of coronary heart disease } \\
\hline & No events/No participants & $\begin{array}{c}\text { Hazard ratio } \\
(95 \% \mathrm{Cl})\end{array}$ \\
\hline \multicolumn{3}{|c|}{ Employment grade: } \\
\hline High & $208 / 2704$ & 1 \\
\hline Middle & $283 / 4370$ & 1.05 (0.88 to 1.26$)$ \\
\hline Low & $128 / 1844$ & $1.29(1.00$ to 1.66$)$ \\
\hline
\end{tabular}

Ethnicity:

\begin{tabular}{lcc}
\hline White & $531 / 8134$ & 1 \\
\hline Other & $88 / 784$ & $1.88(1.50$ to 2.36$)$ \\
\hline
\end{tabular}

Hypertension:

\begin{tabular}{lcc}
\hline No & $425 / 7273$ & 1 \\
\hline Yes & $194 / 1645$ & $1.85(1.55$ to 2.19$)$ \\
\hline
\end{tabular}

Smoking status:

\begin{tabular}{lcc}
\hline Never smoker & $286 / 4461$ & 1 \\
\hline Ex-smoker & $206 / 2893$ & $1.02(0.85$ to 1.22$)$ \\
\hline Current smoker & $127 / 1564$ & $1.42(1.15$ to 1.75$)$ \\
\hline Alcohol consumption: & & \\
\hline Low & $519 / 7515$ & 1 \\
\hline Moderate & $87 / 1198$ & $1.09(0.87$ to 1.37$)$ \\
\hline High & $13 / 205$ & $1.07(0.62$ to 1.86$)$ \\
\hline Exercise: & &
\end{tabular}

Exercise:

\begin{tabular}{llc}
\hline$\geq 1.5 \mathrm{~h} /$ week & $105 / 1659$ & 1 \\
\hline «1.5 h/week & $514 / 7259$ & $1.14(0.92$ to 1.41$)$ \\
\hline Daily fruits and vegetables: & & \\
\hline Yes & $354 / 5260$ & 1 \\
\hline No & $265 / 3658$ & $1.13(0.96$ to 1.32$)$ \\
\hline
\end{tabular}

Body mass index:

\begin{tabular}{|c|c|c|}
\hline$<20$ & $14 / 539$ & 1 \\
\hline $20-24.9$ & $291 / 4960$ & 1.87 (1.09 to 3.20$)$ \\
\hline $25-29.9$ & $250 / 2850$ & 2.60 (1.51 to 4.45$)$ \\
\hline$\geq 30$ & $64 / 569$ & 3.81 (2.13 to 6.80$)$ \\
\hline \multicolumn{3}{|l|}{ Diabetes: } \\
\hline No & $610 / 8837$ & 1 \\
\hline Yes & $9 / 81$ & 1.54 (0.79 to 2.98$)$ \\
\hline
\end{tabular}

\begin{tabular}{lcc}
\hline No & $537 / 7859$ & 1 \\
\hline Yes & $82 / 1059$ & $1.23(0.98$ to 1.56$)$ \\
\hline Blood cholesterol $(\mathrm{mmol} / \mathrm{l}):$ & & \\
\hline$<6.2$ & $288 / 5424$ & 1 \\
\hline$\geq 6.2$ & $331 / 3494$ & $1.55(1.32$ to 1.82$)$ \\
\hline
\end{tabular}


Table $3 \mid$ Associations between positive affect, negative affect, and affect balance scores in thirds and coronary heart disease (number of events/number of participants $=619 / 8918^{\star}$ )

\begin{tabular}{|c|c|c|c|}
\hline \multirow[b]{2}{*}{ Scores in thirds } & \multicolumn{3}{|c|}{ Hazard ratio $(95 \% \mathrm{Cl})$} \\
\hline & Positive affect & Negative affect & Affect balance \\
\hline \multicolumn{4}{|l|}{ Model 1† } \\
\hline Lowest & 1 & 1 & 1 \\
\hline Middle & 1.19 (0.98 to 1.44$)$ & $1.12(0.92$ to 1.36$)$ & 0.97 (0.80 to 1.17$)$ \\
\hline Highest & 1.01 (0.82 to 1.24$)$ & $1.32(1.09$ to 1.60$)$ & 0.89 (0.73 to 1.09$)$ \\
\hline \multicolumn{4}{|l|}{ Model $2 \ddagger$} \\
\hline Lowest & 1 & 1 & 1 \\
\hline Middle & 1.18 (0.97 to 1.43$)$ & 1.13 (0.93 to 1.37) & $0.97(0.80$ to 1.18$)$ \\
\hline Highest & $1.01(0.82$ to 1.25$)$ & $1.33(1.10$ to 1.61$)$ & 0.89 (0.72 to 1.09$)$ \\
\hline \multicolumn{4}{|l|}{ Model 3§ } \\
\hline Lowest & 1 & 1 & 1 \\
\hline Middle & $1.22(1.01$ to 1.48$)$ & 1.15 (0.94 to 1.39$)$ & $0.98(0.81$ to 1.19$)$ \\
\hline Highest & 1.02 (0.83 to 1.26$)$ & 1.37 (1.13 to 1.66$)$ & 0.89 (0.73 to 1.09$)$ \\
\hline \multicolumn{4}{|l|}{ Model 4T } \\
\hline Lowest & 1 & 1 & 1 \\
\hline Middle & 1.20 (0.99 to 1.46$)$ & $1.11(0.92$ to 1.35$)$ & 0.98 (0.81 to 1.19$)$ \\
\hline Highest & 1.03 (0.83 to 1.27$)$ & $1.30(1.07$ to 1.50$)$ & $0.91(0.74$ to 1.11$)$ \\
\hline \multicolumn{4}{|l|}{ Model 5** } \\
\hline Lowest & 1 & 1 & 1 \\
\hline Middle & 1.22 (1.01 to 1.48$)$ & $1.15(0.94$ to 1.40$)$ & $1.00(0.82$ to 1.21$)$ \\
\hline Highest & 1.04 (0.85 to 1.29$)$ & $1.36(1.12$ to 1.65$)$ & 0.91 (0.74 to 1.12$)$ \\
\hline \multicolumn{4}{|l|}{ Model 6†† } \\
\hline Lowest & 1 & 1 & - \\
\hline Middle & 1.26 (1.04 to 1.53$)$ & $1.16(0.95$ to 1.41$)$ & - \\
\hline Highest & 1.10 (0.89 to 1.36$)$ & $1.39(1.14$ to 1.69$)$ & - \\
\hline \multicolumn{4}{|c|}{$\begin{array}{l}\text { * No of events/No (percentage) participants for lowest, middle, and highest scores thirds were 183/2746 (30.8), } \\
257 / 3403 \text { (38.2), and } 179 / 2769 \text { (31) for positive affect; } 208 / 3135 \text { (35.2), 197/2856 (32), and 214/2927 } \\
\text { (32.8) for negative affect; and } 200 / 2817 \text { (31.6), 236/3357 (37.6), and 183/2744 (30.8) for affect balance. } \\
\text { †Hazard ratio adjusted for age, sex, socioeconomic position, and ethnicity. } \\
\text { †Model } 1 \text { additionally adjusted for health related behaviours (body mass index, smoking status, exercise, daily } \\
\text { fruit and vegetable intake, alcohol consumption). } \\
\text { §Model } 1 \text { additionally adjusted for biological risk factors (blood cholesterol, diabetes, hypertension). } \\
\text { †Model } 1 \text { additionally adjusted for psychosocial stress at work. } \\
\star \star \text { Model } 1 \text { + model } 2+\text { model } 3+\text { model } 4 \text {. } \\
\text { ††Model } 5 \text { additionally adjusted for positive or negative affect. }\end{array}$} \\
\hline
\end{tabular}

cases, the pattern of associations was similar to that obtained for measures with replaced missing values.

\section{DISCUSSION}

We examined the associations of positive and negative affect with incident coronary heart disease, followed up over a 12 year period, in the Whitehall II cohort. We found no real association between positive affect or affect balance and incidence of coronary heart disease. Participants in the highest third of negative affect had a slightly increased risk of incident coronary heart disease, and this association remained unchanged after taking into account the effects of age, sex, employment grade, ethnicity, health related behaviours, biological markers, job strain, and positive affect.

\section{Findings in context of the literature and possible mechanisms}

To our knowledge, this is the first prospective cohort study to examine the effects of both negative and positive affect on incident coronary heart disease, independently of known risk factors and of each other. The findings are based on a large well characterised cohort with coronary heart disease ascertained by medical records and biological risk factors assessed by clinical examination.

The finding showing negative affect as an independent predictor of coronary heart disease incidence is consistent with some epidemiological investigations on negative emotions and coronary heart disease. A recent review of negative emotions, measured as anxiety, hostility/anger, and depression, supports their status as risk factors for coronary heart disease. ${ }^{3}$ Anger in men has been found to be associated with a greater risk of coronary events and coronary mortality. ${ }^{2223}$ Among men from the Northwick Park study and women from the Framingham heart study, greater anxiety predicted fatal coronary heart disease. ${ }^{2425}$ According to a recent meta-analysis of 21 aetiological studies and 34 prognostic studies, depressive symptoms are associated with an $80 \%$ excess risk of developing coronary heart disease or dying from coronary heart disease. ${ }^{26}$

The magnitude of the association between negative affect and coronary heart disease in our study is small and needs to be replicated in studies using measures of both positive and negative affect. To test the robustness of our findings, we repeated the analysis using continuous affect scores with assessments of the increase in risk of coronary events across the extremes of the distribution of the affect score. These results also supported the status of negative affect as a risk factor and provided no such support for other affect measures.

Further research is needed to examine the precise mechanisms through which negative affect might increase the risk of coronary heart disease. As negative affect is thought to subsume high negative emotions such as anxiety and depression, ${ }^{827}$ it may be linked to coronary heart disease through physiological (cardiovascular and neuroendocrine) responses related to these emotions. Depression has been found to be associated with pathophysiological changes that may increase the risk of cardiac morbidity and mortality, including autonomic nervous system dysfunction (such as elevated heart rate, low heart rate variability, and exaggerated heart rate responses to physical stressors), ${ }^{28}$ hypothalamic-pituitary-adrenal axis dysregulation (increased cortisol secretion), ${ }^{29}$ enhanced inflammatory processes (higher concentrations of interleukin 6 , C reactive protein, and fibrinogen), ${ }^{30}$ and accelerated progression of atherosclerosis as indicated by change in carotid intima-media thickness. ${ }^{731}$ Negative affect could also be linked to coronary heart disease through health related behaviours. ${ }^{22}$ In our study, negative affect was not associated with hypertension, higher body mass index, or self reported diabetes and was inversely associated with blood cholesterol concentration, suggesting that these factors are not major mediators for the association seen. The association between negative affect and coronary heart disease was not attenuated after adjustment for behavioural factors; thus stable 


\section{WHAT IS ALREADY KNOWN ON THIS TOPIC}

Psychological factors are seen as important predictors of coronary heart disease; negative affectivity may underlie these associations

No large scale study has examined the association between negative affect and coronary heart disease

Whether positive emotions might have a protective role in the development of coronary heart disease remains unclear

\section{WHAT THIS STUDY ADDS}

Negative affect was a weak predictor of incident coronary heart disease in men and women who were free of diagnosed coronary heart disease at recruitment to the study

This association was not accounted for by established coronary risk factors

No support was found for associations of positive affect and affect balance with coronary heart disease in negative affect levels over time and implies that we might have underestimated the cumulative impact of high negative affect on incidence of coronary heart disease. On the other hand, the lack of stability and the relatively low internal consistency coefficient, which was slightly below the conventional threshold of 0.7 for the negative affect scale, call into question what precisely the scale measures. These factors are likely to have influenced our results, and we cannot eliminate the possibility that negative affect might in part represent a marker of changing risk exposures rather than being solely a stable disposition to experience aversive emotional states. However, the proportional hazards assumption held in the Cox regression, suggesting relatively stable effects of negative affect over the follow-up period.

A second limitation involves modelling potential biological and behavioural confounders as time independent covariates. Thus, we did not assess the possible impact of changes in these factors on the risk of coronary heart disease events. Thirdly, our cohort of civil servants did not include blue collar workers and unemployed people and is thus not representative of the general population, which may limit the generalisability of our findings.

\section{Conclusions}

Data from a large occupational cohort provide no evidence for associations between positive affect or affect balance and coronary heart disease in men and women who were free of diagnosed coronary heart disease at recruitment to the study. However, we found negative affect to be weakly predictive of incident coronary heart disease events, independently of sociodemographic characteristics, conventional risk factors, and job strain. Further research is needed to examine whether our findings are generalisable to other populations as well as to disentangle the potential pathways that may link negative affect to coronary heart disease.

Contributors: $\mathrm{HN}$ analysed and interpreted the data and wrote the first draft of the manuscript. MK and AS-M contributed to the analysis and interpretation of data. MK, RDV, MGM, and AS-M made significant contributions to all subsequent revisions. HN is the guarantor. Funding: HN and MK are supported by the Academy of Finland (grant 117604). AS-M is supported by a "EURYI" award from the European Science Foundation and a "Chaire d'excellence" award from the French Ministry of Research. MGM is supported by an MRC research professorship. The Whitehall II study is supported by grants from the Medical Research Council; British Heart Foundation; Health and Safety Executive; Department of Health; National Heart Lung and Blood Institute (HL36310), US, NIH; National Institute on Aging, US, NIH; Agency for Health Care Policy Research (HS06516); and the John D and Catherine T MacArthur Foundation Research Networks on Successful Midlife Development and Socio-economic Status and Health. The funding sources had no role in study design, data collection, data analysis, data interpretation, or writing of the report.

Competing interests: None declared.

Ethical approval: University College London Medical School committee on the ethics of human research gave ethical approval for the Whitehall II study.

Provenance and peer review: Not commissioned; externally peer reviewed. 
1 Yusuf S, Reddy S, Ounpuu S, Anand S. Global burden of cardiovascular diseases. Part II: variations in cardiovascular disease by specific ethnic groups and geographic regions and prevention strategies. Circulation 2001;104:2855-64.

2 Yusuf S, Reddy S, Ounpuu S, Anand S. Global burden of cardiovascular diseases. Part I: general considerations, the epidemiologic transition, risk factors, and impact of urbanization. Circulation 2001;104:2746-53.

3 Kubzansky LD, Kawachi I. Going to the heart of the matter: do negative emotions cause coronary heart disease? J Psychosom Res 2000;48:323-37.

4 French-Belgian Collaborative Group. Ischemic heart disease and psychological patterns: prevalence and incidence studies in Belgium and France. Adv Cardiol 1982;29:25-31.

5 Suls J, Bunde J. Anger, anxiety, and depression as risk factors for cardiovascular disease: the problems and implications of overlapping affective dispositions. Psychol Bull 2005;131:260-300.

6 Yan LL, Liu K, Matthews KA, Daviglus ML, Ferguson TF, Kiefe Cl. Psychosocial factors and risk of hypertension: the coronary artery risk development in young adults (CARDIA) study. JAMA 2003;290:2138-48

7 Stewart JC, Janicki DL, Muldoon MF, Sutton-Tyrrell K, Kamarck TW. Negative emotions and 3-year progression of subclinical atherosclerosis. Arch Gen Psychiatry 2007;64:225-33.

8 Watson D, Clark LA. Negative affectivity: the disposition to experience aversive emotional states. Psychol Bull 1984;96:465-90.

9 Watson D, Clark LA, Tellegen A. Development and validation of brief measures of positive and negative affect: the PANAS scales.J Pers Soc Psychol 1988;54:1063-70.

10 Hemingway $\mathrm{H}$, Marmot $\mathrm{M}$. Psychosocial factors in the aetiology and prognosis of coronary heart disease: systematic review of prospective cohort studies. BMJ 1999;318:1460-7.

11 Clark LA, Watson D. Tripartite model of anxiety and depression: psychometric evidence and taxonomic implications. J Abnorm Psychol 1991;100:316-36.

12 Diener E, Emmons RA. The independence of positive and negative affect. J Pers Soc Psychol 1984;47:1105-17.

13 Ostir GV, Markides KS, Peek MK, Goodwin JS. The association between emotional well-being and the incidence of stroke in older adults. Psychosom Med 2001;63:210-5.

14 Hamer DH. The heritability of happiness. Nat Genet 1996;14:125-6.

15 Marmot M, Brunner E. Cohort profile: the Whitehall II study. Int Epidemiol 2005;34:251-6.

16 Bradburn NM, Noll CE. The structure of psychological well-being. Chicago, IL: Aldine, 1969.

17 Rose GA. Cardiovascular survey methods. 2nd ed. Geneva: World Health Organization, 1982

18 Gutzwiller F. Monitoring of cardiovascular disease and risk factor trends: experiences from the WHO/MONICA project. Ann Med 1994;26:61-5
19 Karasek R, Theorell T. Healthy work: stress, productivity, and the reconstruction of working life. New York: Basic Books, 1990.

20 Landsbergis PA, Schnall PL, Warren K, Pickering TG, Schwartz JE. Association between ambulatory blood pressure and alternative formulations of job strain. Scand J Work Environ Health 1994;20:349-63.

21 Kuper H, Marmot M, Hemingway H. Systematic review of prospective cohort studies of psychosocial factors in the etiology and prognosis of coronary heart disease. Semin Vasc Med 2002;2:267-314.

22 Kawachi I, Sparrow D, Spiro A 3rd, Vokonas P, Weiss ST. A prospective study of anger and coronary heart disease: the normative aging study. Circulation 1996;94:2090-5.

23 Koskenvuo M, Kaprio J, Rose RJ, Kesaniemi A, Sarna S, Heikkila K, et al. Hostility as a risk factor for mortality and ischemic heart disease in men. Psychosom Med 1988;50:330-40.

24 Haines AP, Imeson JD, Meade TW. Phobic anxiety and ischaemic heart disease. BMJ 1987;295:297-9.

25 Eaker ED, Pinsky J, Castelli WP. Myocardial infarction and coronary death among women: psychosocial predictors from a 20-year followup of women in the Framingham Study. Am J Epidemiol 1992;135:854-64.

26 Nicholson A, Kuper H, Hemingway H. Depression as an aetiologic and prognostic factor in coronary heart disease: a meta-analysis of 6362 events among 146538 participants in 54 observational studies. Eur Heart/ 2006;27:2763-74.

27 Polk DE, Cohen S, Doyle WJ, Skoner DP, Kirschbaum C. State and trait affect as predictors of salivary cortisol in healthy adults. Psychoneuroendocrinology 2005;30:261-72.

28 Carney RM, Freedland KE, Veith RC. Depression, the autonomic nervous system, and coronary heart disease. Psychosom Med 2005;67(suppl 1):S29-33.

29 Grippo AJ, Johnson AK. Biological mechanisms in the relationship between depression and heart disease. Neurosci Biobehav Rev 2002;26:941-62.

30 Miller GE, Stetler CA, Carney RM, Freedland KE, Banks WA. Clinical depression and inflammatory risk markers for coronary heart disease. Am J Cardiol 2002;90:1279-83.

31 Paterniti S, Zureik M, Ducimetiere P, Touboul PJ, Feve IM, Alperovitch A. Sustained anxiety and 4-year progression of carotid atherosclerosis. Arterioscler Thromb Vasc Biol 2001;21:136-41.

32 Huppert FA, Baylis N, Keverne B. The science of well-being: integrating neurobiology, psychology and social science: papers of a discussion meeting. London: Royal Society, 2004.

33 Pressman SD, Cohen S. Does positive affect influence health? Psychol Bull 2005;131:925-71.

34 Blazer DG, Hybels CF. What symptoms of depression predict mortality in community-dwelling elders? J Am Geriatr Soc 2004;52:2052-6.

Accepted: 24 April 2008 